\title{
Treatment of acute type b aortic dissection: New and improved?
}

\author{
R. Scott Mitchell, MD
}

See related article on page 1380.
From Falk Cardiovascular Research Center, Stanford University Medical Center, Stanford, Calif.

Received for publication June 12, 2007; accepted for publication July 5, 2007.

Address for reprints: R. Scott Mitchell, MD, Falk Cardiovascular Research Center, Stanford University Medical Center, Stanford, CA 94305-5407 (E-mail: rsmitch@ stanford.edu).

J Thorac Cardiovasc Surg 2008;135:1201

0022-5223/\$34.00

Copyright (C) 2008 by The American Association for Thoracic Surgery

doi:10.1016/j.jtcvs.2007.07.072
T The utility of endovascular stent grafts for the treatment of complicated type $\mathrm{b}$ aortic dissections, especially involving malperfusion, has been well established, at least in the short term. These patients are generally quite compromised, with impaired visceral perfusion and end organ dysfunction. The case herein reported by Iannelli and colleagues ${ }^{1}$ is not clearly complicated, although emergency surgical intervention was "considered because of the substantial risk of impending rupture." Persistent pain and hypertension in the short term may just require more aggressive therapy. Although the ascending aorta is described as $42 \mathrm{~mm}$, the diameter of the proximal descending thoracic aorta is not given, and the necessity for any emergency therapy is unclear.

Although the procedure described is indeed innovative, and "accomplished under local anesthesia," a retroesophageal Dacron carotid-to-carotid bypass with left carotid ligation hardly seems a desirable long-term solution. Similarly, coverage of the entire dissected descending thoracic aorta with a stent graft entails a significant risk of paraplegia, which was fortunately, and fortuitously, avoided. In addition, the origin of the various visceral vessels (Celiac Artery, Superior Mesenteric Artery, Right Radial Artery, Left Radial Artery) is not described. In the postrepair computed tomographic angiogram, only the RRA appears to arise from the true lumen, making adequate perfusion of the CA, SMA, and LRA dependent on patency of the false lumen, which is excluded. Certainly, for the long term, this circulation seems less than ideal, with all head vessels arising from the innominate artery, and three of four visceral vessels arising from an imperiled false lumen.

In an otherwise healthy 56-year-old man, a definitive surgical repair using hypothermic circulatory arrest and proximal descending thoracic aortic replacement is a widely performed technique with modest morbidity. If any surgical procedure was necessary, and that point remains unclear, durability in a 56-year-old patient is a significant consideration. The quoted risk of $7 \%$ to $36 \%$ paraplegia rates for operations confined to the descending thoracic aorta hardly reflects current results in experienced centers and may more accurately describe the risk of paraplegia for stent-graft coverage of the entire descending thoracic aorta with an acute dissection. The metaanalysis (reference 4 ) described by the authors is largely composed of chronic dissections $(40 \%)$, with no case described as requiring complete coverage of a dissected thoracic aorta.

Certainly, we should be prepared to embrace new technologies if they provide improved outcomes. However, for the uncomplicated acute type b dissection, the best evidence to date (INSTEAD trial ${ }^{2}$ ) suggests worse 1-year outcomes for patients treated with stent grafts versus best medical therapy. Before we prematurely use a new technology, we must first ascertain that it is in the patients' best interests, both short and long term.

\section{References}

1. Innaelli G, Monaco M, Di Tommaso L, Piscione F. Complicated acute type B aortic dissection involving the arch: Treatment by simultaneous hybrid approach under local anesthesia. J Thorac Cardiovasc Surg. 2008; $135: 1380-2$.

2. Nienaber C. Results from the INSTEAD trial. Sixth Annual International Symposium on Advances in Understanding Aortic Diseases. Berlin, Germany. Sept 30-Oct 1, 2005. 